\title{
VEDIC MATHEMATICS
}

\section{Sead Rešić \\ Adin Lemo}

Department of Mathematics, Faculty of Sciences, University of Tuzla ${ }^{1}$

Technical school Silvija Strahimira Kranjčevića, Livno, B\&H
Original scientific paper
Received: 06.07.2015

Accepted: 23.08.2015
UDC: $51-32: 233-24$

371.3:51

\begin{abstract}
It is very difficult to motivate students when it comes to a school subject like Mathematics. Teachers spend a lot of time trying to find something that will arouse interest in students. It is particularly difficult to find materials that are motivating enough for students that they eagerly wait for the next lesson. One of the solutions may be found in Vedic Mathematics. Traditional methods of teaching Mathematics create fear of this otherwise interesting subject in the majority of students. Fear increases failure. Often the traditional, conventional mathematical methods consist of very long lessons which are difficult to understand. Vedic Mathematics is an ancient system that is very flexible and encourages the development of intuition and innovation. It is a mental calculating tool that does not require a calculator because the calculator is embedded in each of us. Starting from the above problems of fear and failure in Mathematics, the goal of this paper is to do research with the control and the experimental group and to compare the test results. Two tests should be done for each of the groups. The control group would do the tests in the conventional way. The experimental group would do the first test in a conventional manner and then be subjected to different treatment, that is to say, be taught on the basis of Vedic Mathematics. After that, the second group would do the second test according to the principles of Vedic Mathematics. Expectations are that after short lectures on Vedic mathematics results of the experimental group would improve and that students will show greater interest in Mathematics.
\end{abstract}

Keywords: Vedic Mathematics, Sutras, complement, deviations, pretest, posttest

\section{INTRODUCTION: What is Vedic Mathematics?}

Vedic Mathematics is a mathematical system that is more than 5000 years old. The word "Veda" in Sanskrit, which is now a "dead" language, means knowledge .Vede include not only the knowledge of mathematics. Specifically, there are four types of the Vedas: Rig Veda, Samaveda, Yajurveda and Atharvaveda (Dasgupta, 2012). In The Encyclopaedia Of Indian Literature (2001) cited four Upravede: Ayurveda, Gandharvaveda, Dhanurveda and Sthapatyaveda. Vedic Mathematics is part Sthapatyaveda, "the science of construction," which dealt with architecture, civil engineering and Mathematics. Sri Bharati Krsna Tirthaji $(1884-1960)$ in the period from 1911 to 1918 studied the mathematical system in the Veddas and the proved and proved to the world that the Vedic mathematics is not only applicable to the Sanskrit language. He found that the system makes 16 Sutras and 14 auxiliary Sutra in Sanskrit. Sutras are, in fact, a simple formula described with a few words. These are easy to understand and can be used in various branches of mathematics.

\footnotetext{
${ }^{1}$ Correspodence to:

Sead Rešić, Department of Mathematics, Faculty of Sciences, University of Tuzla

Šabana Zahirovića 10, Tuzla, B\&H

Phone: +38761 101230

E-mail: sresic@hotmail.com
} 
Sutras are:

Ekadhikena Purvena : By one more than the previous one

Nikhilam Navatashcaramam Dash : All from 9 and the last from 10

Urdhva-tiryagbhyam : Vertical and diagonal

Paraavartya Yojayet : Transpose and adjust

Shunyam Saamyasamuccaye :If the total/combination is same, it should be zero

(Anurupye) Shunyamanyat : If one is in ratio, other is zero

Sankalana-vyavakalanabhyam : By addition and by subtraction

Puranapuranabhyam : By the completion or noncompletion

Chalana-Kalanabhyam : Differential calculation

Yaavadunam : Whatever the extent of its deficiency

Vyashtisamanshtih : Part and whole

Shesanyankena Charamena: The remainders by the last digit

Sopaantyadvayamantyam : The ultimate and twice the penultimate

Ekanynena Purvena : By one less than the previous one

Gunitasamuchyah : The product of the sum is equal to the sum of the product

Gunakasamuchyah : The factors of the sum is equal to the sum of the factors

Apart from these 16 Sutras, there are 16 Sub Sutras (Auxiliary sutras):

Proportionately

The remainder remains constant

The first by the first and the last by the last

For 7 the multiplicand is 143

By osculation

Lessen by the deficiency

Whatever the deficiency lessen by that amount and set up the square of the deficiency

Last totalling 10

Only the last terms

The sum of the products

By alternative elimination and retention

By mere observation

The product of the sum is the sum of the products

On the flag

Vedic Mathematics is a branch of mathematics and stands alongside geometry, trigonometry, arithmetic and other branches of mathematics and, in addition to basic arithmetic operations of addition, subtraction, multiplication and division, it is also used to potenti- ate, square root, work with derivatives and integration. Vedic Mathematics is slowly but surely finding its way into primary and secondary schools. This ancient but for many an unknown system is increasingly studied and in the future will find its place among students of all generations, because of its simplicity, the possibilities of faster calculation and flexibility.

\section{Definition and importance of the research prob- lem}

Many students have a fear of Mathematics. In high school they avoid to learn and practice Mathematics for various reasons. Many are afraid of failure. Some argue that the teachers and professors of Mathematics are strict, that they are asking too much of them. In addition, most are of the opinion that the traditional methods are difficult, boring and monotonous. The question is, in what way can we act to remove these fears and attract students to love Mathematics? Answers to this question may be difficult to offer, but it certainly is worth the effort.

Students use calculators and mobile phones to multiply two-digit numbers. Those are elementary mistakes and create aversion to Mathematics. Because that particular problem is not simple, we opted for Vedic Mathematics to show that the "new", easier, more interesting procedures may interest students. In order to induce students' interest for this not very much liked subject, we introduced a small number interesting lectures.

The research problem is related to the question of whether and to what extent Vedic Mathematics can help improve success in mathematics, but also a change in attitudes about Mathematics. We are witnessing a very quick lifestyle with a lot of competitive spirit. By applying the methods of Vedic Mathematics we can achieve a positive competitive spirit because it allows an increase in the speed of computing with less effort. Traditional, conventional mathematical methods are monotonous, long and boring. The subject of this research are methods of Vedic Mathematics which assist students in improving their success.

\section{Research objectives}

Based on the case studies objectives are set as follows:

- study and review the effectiveness of the learning processes of Vedic Mathematics compared to conventional methods, 
- whether there is a statistically significant difference between mean values of the results of the experimental and control groups on the pretest,

- whether there is a statistically significant difference between mean values of the results of the experimental and control groups on the posttest.

\section{Research tasks}

The main tasks of the research are:

- to examine and determine whether there is a statistically significant difference in the average scores of the experimental group and the control group in pre-testing,

- to examine and determine whether there is a statistically significant difference in the average scores of the experimental group and the control group on the posttest.

\section{Hypotheses}

Hypothesis 1: There is no statistically significant difference in the average scores of the experimental group and the control group in pre-testing.

Hypothesis 2: There is a statistically significant difference in the average scores of the experimental group and the control group on the posttest.

\section{Research Methods}

The method of theoretical analysis is analysis of scientific papers, books, scientific journals etc, and this method is used to create a theoretically based research and to notice aspects of the research problem. In accordance with the scope, objectives, tasks of research, the nature of the problem and the hypotheses in the study, the experimental method was used. The goal is to determine the difference between the state before the exeperiment and final state after the introduction of the experiment. The aim of the experiment in this study is introduction of methods of Vedic Mathematics. This is an experiment with parallel groups: the experimental group and the control group. The control group does both tests by conventional methods. The experimental group does the first test (pretest) by conventional method after which the group has lectures on Vedic Mathematics (Appendix 2). Pretest and posttest are also attached.

In order to acquire data the technique of testing by pretest and posttest was used. Data assortmenttechnique and statistical analysis of data were used to test the stated hypotheses.

\section{Research sample}

The sample of this research is deliberate and appropriate, consisting of students of Technical school. The total sample consists of 60 students, 30 in the experimental group, 30 makes the control group.

\section{Organization and flow of research}

1) Research was carried out from October 13 to November 15, 2014.

2) Data processing till November 30, 2014.

\section{Analysis of the results after the pretest}

Table 1. Differences in mean values of the control and experimental groups at pretest

\begin{tabular}{lcccccc}
\hline Group & N & M & SD & Difference M & t-value & p \\
\hline Control & 30 & 5.97 & 1.92 & & .07 & .141 \\
Experimental & 30 & 5.90 & 1.73 & & & .888 \\
\hline
\end{tabular}

Table tells us the following: the number of subjects in the pretest is 30 for the control and the experimental group. For the control group, the arithmetic mean of the results of pretest is $\mathrm{M}=5.97$, for the experimental group, the arithmetic mean of the results is $M=5.90$. Mean difference was 0.07 and the advantage is in fa- vor of the control group. The significance of 0.05 was used for the test. The calculated t-value is 0.141 with a significance of 0.888 , which is above 0.05 and indicates that there is no statistically significant difference in the average scores of the experimental group and the control group in pre-testing. 
Analysis of the results after the posttest

Table 2. Differences in mean values of the control and experimental groups after posttest

\begin{tabular}{lcccccc}
\hline \multicolumn{1}{c}{ Group } & $\mathbf{N}$ & $\mathbf{M}$ & $\mathbf{S D}$ & Difference M & t-value & $\mathbf{p}$ \\
\hline Control & 30 & 5.93 & 1.60 & & & \\
& & & & -0.97 & -2.339 & .023 \\
Experimental & 30 & 6.90 & 1.60 & & & \\
\hline
\end{tabular}

After the analysis of Table 2 we come to the conclusion that confirms the second hypothesis: there is a statistically significant difference in the average scores of the experimental group and the con- trol group at posttest in favor of the experimental group. The size of Etha square indicates that the difference is moderate.

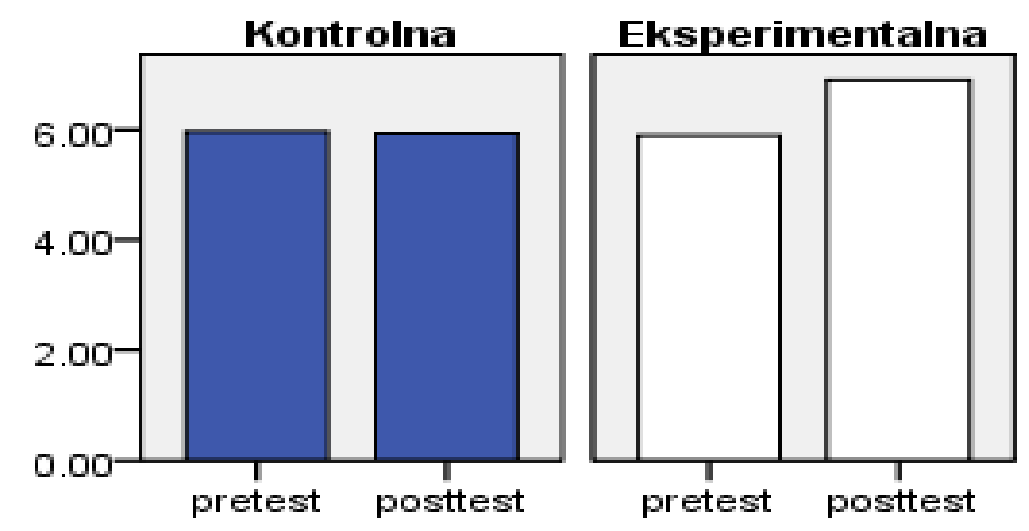

Control (kontrolna) and experimental (eksperimentalna) groups

Chart 1 shows the comparative results of the control and experimental groups at pretest and posttest. The first part of the graph are the results of the control group on tests. It is evident that the results are uniform in the group that worked by conventional methods. The second part of the graph are the results of the experimental group. It is evident that the results after the experimental treatment and after working on methods of Vedic Mathematics improved.

\section{CONCLUSION}

Students and their parents, teachers, professors live today in a time of competition. That competition is naturally transmitted to the classroom. In today's fastpaced life, not many students spend time learning and practicing Mathematics. This is a subject that is not popular amongst them. Most students fearof poor results and failure in Mathematics. There is a need to find something that will interest them in Mathematics, something new for them to be interesting and at the same time useful. The solution can be found in Vedic Mathematics.

Vedic Mathematics is something that everyone liked at "the first try". Through the Sutras it allows flexibility and breaks up the monotony of the long journey of computation as in traditional practices. Square number 45 calculated by heart - they thought it was impossible, and only calculate the cube root number 12167 - mission impossible. Procedures in Vedic Mathematics allow calculating square and cube roots in a very short time. All this is possible to learn in several short lessons.

The assumption of the first hypothesis in the study was that there was no statistically significant difference in the average scores of the experimental group and the control group in pretesting. The sample consisted of 30 students in the experimental and control groups. Pretest (Appendix 1) was the same for both groups and confirmed the first hypothesis because the results were uniform. 
After the test the experimental group had the lectures on theoretical bases of Vedic Mathematics and ways of multiplication and square root procedures in Vedic Mathematics (Appendix 2). After this the posttest was done (Appendix 3), which was the same for both groups. The test confirmed the second hypothesis that there is a statistically significant difference in the average scores of the experimental group and the control group on the posttest.

In Vedic Mathematics there is an emphasis on meaningful, not on mechanical learning. During a lecture in the experimental treatment, the students were more interested than usually and built a better relationship with the teacher, better interaction and communication. This manner of teaching arouses the interest in students and creates a positive opinion, positive attitude about Mathematics. Teaching Mathematics through Vedic Mathematics is easier to understand than with traditional methods. After solving the basic tasks, students themselves look for more and more complex tasks to solve.

The conclusion is that Vedic Mathematics can removethe notorious fear of Mathematics. Vedic Mathematics enables better success but also speed, compared to traditional, conventional Mathematics. The scientist and mathematician Dr. Kenneth Williams saidafter exploring Vedic Mathematics: "It is so fascinating, it turned math-haters in math-lovers!".

Calculators are now popular with students, every day they are in their smartphones. Students even use them and to multiply two-digit numbers. Methods of Vedic Mathematics computing are interesting and students do not make mistakes as with traditional methods. Students should use the calculator that is embedded in all of us and Vedic Mathematics should be the right hand of our calculator.

\section{REFERENCES}

Dasgupta, S. (2012). A History of Indian Philosophy, Volume 1. New Delhi: Motilal Banarsidass

Kumar, P. (2014). Vedic Mathematics, Bregana: Hars

The Encyclopaedia Of Indian Literature (2001). New Delhi: Sahitya Akademi

Vedic mathematics Academy (2005). Research in vedic math. Vedic mathematics newsletter issue 00045, available at: http:// www.vedicmaths.org/2005-newsletter-index/45-research-invedic-math (accessed 12 November 2014)

http://www.magicalmethods.com/FREE/EOVM_R_Apik.pdf (accessed 01 November 2014)

\section{APPENDIX}

\section{Appendix 1 Pretest}

\section{Vedic Mathematics}

This is an anonymous test. This is a research on efficiency of Vedic Mathematics. The intention is that by introducing you to unknown methods, you can optimize success and remove the fear of Mathematics.

Start time:

End time: (only researcher)

Thank you for your cooperation.

Calculate:

$43 \cdot 47$

96.99

$109 \cdot 108$

$348 \cdot 11$

$5682 \cdot 11$

$57^{2}$

$95^{2}$

$\sqrt[2]{2116}$

$\sqrt[3]{1728}$

$\sqrt[3]{27000}$

\section{Appendix 2}

\section{Vedic Mathematics-short lectures}

Vedic Mathematics is a mathematical system that is more than 5000 years old. The word "Veda" in "dead" language Sanskrit means knowledge. Sri Bharati Krsna Tirthaji (1884-1960) in the period from 1911 to 1918 studied the mathematical system in the Vedas and the proved to the world that the Vedic mathematics is not only applicable to the Sanskrit language. He found that the system is made of 16 Sutras and 14 auxiliary Sutras in Sanskrit. Sutras are, in fact, a simple formula described with a few words. 


\section{- Multiplication}

Examples:

\section{- Multiplication}

Examples:

a) $35 \times 35=1225$

Procedure: 1) $5 \times 5=25$

2) $3+1=4$

3) $4 \times 3=12$

b) $114 \times 116=13224$

Procedure : 1) $4 \times 6=24$

2) $1+1=12$

3) $12 \times 11=132$

c) $98 \times 96$



94 / $08 \quad$ (crossing : 96-2=94 ili 98-4=94 )

$98 \times 96=9408$

d) $95 \times 93$



$88 / 35$

(crossing : 93-5=88)

$95 \times 93=8835$

e) $105 \times 107$

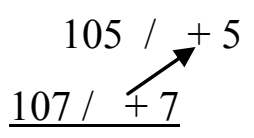

$$
\begin{gathered}
112 /+35 \\
=11235
\end{gathered}
$$

$$
\begin{aligned}
\text { f) } 236 \times 11 & \text { 1) } 0+2=2 \\
02360 & \text { 2) } 2+3=5 \\
=2596 & \text { 3) } 3+6=9 \\
& \text { 4) } 6+0=6 \text { b) } 854 \times 111
\end{aligned}
$$


In the example shown the squaring the number 105 in a number of ways :

a) $105^{2}=105+5$

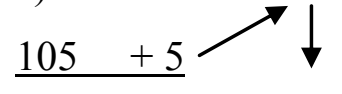

$110 \quad 25$

b) $105^{2}=105 \times 105=/(10+1) \times 10 / 5 \times 5=11025$

c) $105^{2}=10^{2} / 2 \times 10 \times 5 / 5^{2}=/ 100 / 100 / 25=11025$

d) $(105)^{2}=(100+5)^{2}=100^{2}+2 \times 100 \times 5+5^{2}=10000+1000+25=11025$

\section{- Square Root}

a) $\sqrt{15129}=$ ?

Number of digits solutions is $(n+1) / 2=(5+1) \div 2=6 \div 2=3$.

\begin{tabular}{c|c}
$1: 51: 29$ \\
2 & $01 \quad 10$ \\
\hline & 123.00
\end{tabular}

Step $1: 1^{2}=1 ; 1-1=0$

Step $2: 2 \times 1=2 ; 05 \div 2=2 \mathrm{R} 1$

Step 3: $11-\mathrm{D}(2)=11-2^{2}=11-4=7$;

$$
7 / 2=3 \text { R } 1
$$

Step $4: 12-\mathrm{D}(23)=12-12=0$;

$$
0 / 2=0 \text { R } 0
$$

Step 5: $09-\mathrm{D}(3)=09-3^{2}=0 \quad: \quad \sqrt{15129}=123$

b) $\sqrt{4761}=$ ? Number of digits solution is $n \div 2=4 \div 2=2$.

\begin{tabular}{c|c} 
& $47: 6$ \\
12 & $11 \quad 8$ \\
\hline & 69.0
\end{tabular}

Step 1: $6^{2}=36 ; 47-36=11$, Step $2: 2 \times 6=12 ; 116 \div 12=9$ R 8

Step 3: $81-9^{2}=81-81=0 \quad$ Solution : 69

c) $\sqrt{970225}=$ ? Number of digits solutions is $n / 2=6 \div 2=3$.

\begin{tabular}{c|c}
$97: 02$ & $2: 25$ \\
18 & 161682 \\
\hline & 985.00
\end{tabular}




\section{The third root}

A technique explained here only applies to the cubes of integers, and this is very good and practical way to determine the approximate value. It is necessary to know the third potency of numbers from 1 to 9 .

$\begin{array}{lll}1^{3} & = & 1 \\ 2^{3} & = & 8 \\ 3^{3} & = & 27 \\ 4^{3} & = & 64 \\ 5^{3} & = & 125 \\ 6^{3} & = & 216 \\ 7^{3} & = & 343 \\ 8^{3} & = & 512 \\ 9^{3} & = & 729 \\ \sqrt[3]{4913} & \end{array}$

) $\sqrt[3]{4913}=$ ?

Step1. : put a comma after you determine three places from the right: 4,913

Step 2. : go to the last group of digits (913) and we see that the last digit is (3). Then the digit is compared with the values of the cubes of numbers from 1 to 9 , we take the number $7(73=343)$ as the last digit solution

Step 3. : looking at the first digit or group of digits: 4 and compare with values cubes of numbers from 1 to 9 , we take the number 1 as the first digit of solutions because

$\left(1^{3}=1\right)<4<\left(2^{3}=8\right)$

solution : $17: 17^{3}=4913$

b) $\sqrt[3]{19683}=/ 19 / 683 /=27$

We take the number 7 as the last digit solution because $7^{3}=343$ ( 3 the last digit number 683)

We take the number 2 as the first digit of solutions because $2^{3}=8<19<3^{3}=27$

c) $\sqrt[3]{15625}$

Step 1. : put a comma after you determine three places from right: 15,625

Step 2. : go to the last group of digits (625) and we see that the last digit is (5). The digit is compared with the values of the cubes of numbers from 1 to 9 , we take the number $5\left(5^{3}=125\right)$ as the last digit solution

Step 3. : Looking at a group of digits: 15 and compared with the values of the cubes of numbers from 1 to 9 , we take the number 2 as the first digit of solution because

$\left(2^{3}=8\right)<15<\left(3^{3}=27\right)$

Solution : 25 :

$\sqrt[3]{15625}=25 ; 25^{3}=15625$

\section{Appendix3:}

\section{Posttest}

\section{Vedic Mathematics}

This is an anonymous test. This is a research on efficiency of Vedic Mathematics. The intention is that introducing unknown methods optimize success and remove the fear of Mathematics.

Start time:

End time: (only researcher)

Thank you for your cooperation.

Calculate:

$48 \cdot 42$

$96 \cdot 98$

$103 \cdot 105$

$236 \cdot 11$

$7218 \cdot 11$

$45^{2}$

$61^{2}$

$\sqrt[2]{2704}$

$\sqrt[3]{4913}$

$\sqrt[3]{39304}$ 